\title{
BREVE REFLEXĀO SOBRE O SUBSTANTIVO COLETIVO
}

\author{
JOSE LUIZ MERCER
}

I. A Noção de Substantivo Coletivo.

\section{O que é um substantivo coletivo?}

Na, classificação dos substantivos, a Gramática Tradicional esta. belece entre os substantivos comuns o subgrupo dos substantivos coletivos. Estes substantivos se caracterizam pelo fato de o seu significado exprimir uma pluralidade de seres: VARA, por exemplo, indica um conjunto de porcos. O substantivo coletivo se opõe, portanto, ao substantivo unirário, ou seja, àquele que significa apenas um inalvíduo: POR'CO, v.g.

Como o substantivo unitário, uma vez colocado no plural (PORCOS, p. ex.), também pode indicar uma pluralidade de seres, importa aqui afinar a distinção entre substantivo unitário e substantivo coletivo. Neste, a idéia de pluralidade já está contida no semantismo do seu radical, enquanto o subsiantivo unitário só remete a uma pluralidade se provido de uma desinência de plural. Em VARA, a pluralidade é veiculada pelo radical, e em PORCOS, pela desinência de plural $/-s /\left(^{1}\right)$. O simples jogo de flexão numérica não produz confusão: no singular, PORCO remete a um indivíduo e VARA a um conjunto de indivíduos; no plural, PORCOS indica diversos indivíduos, ao passo que VARAS significa diversos conjuntos de indivíduos.

Por esse cotejo percebe-se que há, ao menos aparentemente, uma identidade entre PORCOS e VARA. E é lícito perguntar por que a língua, um sistema altamente econômico, abrigaria dois termos equivalentes: o plural do termo indicativo da espécie e o coletivo dessa espécie. A resposta não é difícil: PORCOS e VARA não têm o mesmo significado. O termo VARA indica que os indivíduos se encontram reunidos num ponto do espaço e do tempo. VARA são alguns porcos próximos uns dos outros (espaço) num determinado momento (tem- 
po). Já no caso de PORCOS, o plural náda diz sóbre o lugar e o tempo em que se siluam os indivíduos: bem pode ser o mesmo, bem pode variar de um individuo para outro. Quando digo que Pedro tinha uma VARA, fica entendido que os porcos de Pedro estavam reunidos num determinado lugar, durante algum tempo. Mas se digo que Pedro tinha PORCOS, não fica explicitado se esses porcos estavam reunidos em um mesmo lugar, ou ainda se eram contemporâneos uns dos outros.

O coletivo e o plural remetem à mesma categoria semântica, a da pluralidade, entendida como expressão de um conjunto de seres aos quais a língua reconhece uma individualidade e atribui uma natureza comum. No interior dessa categoria, no entanio, manifestam subcategorias distintas. O piural exprime a forma mais simples i.e., a menos compreensiva - de pluralidade, ao passo que as coletivo corresponde uma pluralidade particularizada pelo fato de o conjunto de seres representado estar integrado por uma relação de agrupamento no tempo e/ou no espaço. A coletividade - chamemos as. sim a subcategoria realizada pelo coletivo - é uma forma marcada, por oposição à pluralidade simples, que seria a forma não marcada. Aliás, pode-se prever inúmeras outras subcategorias da pluralidade, todas marcadas: a pluralidade inclusiva, como a expressa por NOS e VOS, a universal, como em O HOMEM é mortal, a quantificadora, tradUzida poi itens como SECULO, etc. Fixemos, pois, uma oposição fundamental entre plural e coletivo: aquele apresenta uma quantidade, sem mais, enquanto este exprime uma unidade feita de quantidade - entendendo que o coletivo dá o conjunto de seres como um só ser.

Mas se o coletivo indica uma unidade - feita de quantidade -, em que difere do substantivo unitário? Se podemos entender que VARA significa um indivíduo (constituído de uma pluralidade de seres), que diferença há, desse ponto de vista, entre VARA e RELOGIO, vendo-se neste um conjunto de peças? Há pelo menos duas razōes para recusar a RELOGIO a condição de coletivo. A primeira se prende so fato de que por coletivo se entende a representação de um grupo de indivíduos que podem ocorrer isolados, de modo que se deixam definir sem referência à coletividade que eventualmente formem. $\mathrm{PI}$ NHEIRO, por exemplo, é noção que não depende da de PINHEIRAL. Ora, as peças do RELOGIO só são peças por referência ao relćgio. A segunda razão está em que RELÓGIO não apresenta a coisa relógio como uma pluralidade de peças, por mâis que possamos ver a coisa relógio como uma plu:alidade de peças. Esta questão mostra a neces- 
sidade de distinguir rigorosamente dois objetos, unidos por uma relação de correspondência semiótica: a entidade lingüística e a coisa a que remete essa entidade. Como a qualidade de coletivo é atributo apenas da entidade lingüística, segue-se que a um objeto composto não corresponderá necessariamente um nome coletivo, porquanto cabe à língua - como instrumento de cultura - decidir que objetos serão por ela considerados como coletividades e que por conseguinte terão nomes de natureza coletiva. As palavras - cabe aqui lembrar - não são meras etiquetas das coisas: entre o vocabulário e o mundo ergue-se a rede lingüística de objetificação e de classificação( $\left.{ }^{2}\right)$. Assim, não será pela natureza do ente nomeado que se chegará às qualidades lingüísticas do seu nome. Apenas critérios fornecidos pela própria língua nos permitirão reconhecer um coletivo como tal.

Se fosse o caso de multiplicar os exemplos de que é a língua que decide que termos serão coletivos, haveria uma infinidade de vocábulos a citar: TECIDO não é o coletivo de fios, nem REDE de malhas, nem PENEIRA de furos, etc.

\section{Existem realmente coletivos?}

A esta altura, pode-se até mesmo pôr em questão a existência de coletivos. Haveria algo na língua que corresponde à noção de coletivo, ou trata-se aí de uma fiç̧ão gramatical? Sendo pacífico que os coletivos não constituem uma subclasse formal dos substantivos, trata-se de averiguar a possibilidade de formarem uma subclasse semântica. Afora um vago sentimento lingüístico, apenas dois fatos positivos militam a favor da pertinência do coletivo. O primeiro é a existência de sufixos derivacionais que trazem a idéia de coletivo; 0 segundo é o caso de silepses como: "A turma. são fogo", "O povo estavam com fome", etc. Os sufixos, por si sós, não sustentam a noção de coletivo como categoria lingüística: a ninguém ocorreria postular a existência de uma categoria de "patologia", em português, à simples consideração de sufixos como /-ite/ e /-ose/. Em todo caso, não passa despercebido que os sufixos de coletivo são em número significativo. Tampouco o segundo fato é conclusivo, pois silepses dessa natureza ocorrem também com vocábulos que gramático algum faria figurar numa lista de coletivos. Tal é o caso dos antropônimos, que em ambiente familiar podem assumir caráter pluralício: "Sérgio foram almoçar fora" (entende-se "Sérgio e os seus foram almoçar fora"). Tais exemplos deixam ver que esse tipo de silepse se dá em virtude da significação pluralícia dos termos TURMA ou SERGIO, e não em função de um traço mais específico, de coletivo, que estaria presente em TURMA, mas não em SERGIO. Com efeito, este último 
termo, ainda significando "Sérgio e seus familiares" ou "a família de Sérgio", não é um coletivo (como no caso do relógio e suas peças, os familiares de Sérgio só se definem como tais por referência à "familia de Sérgio"). E mais: devesse distinguir vocábulo plu:alício, como gênero, de vocábulo coletivo, como espécie. O primeiro é trdo vocábulo que, por seu significado, exprime uma pluralidade; o segundo é um caso especial do anterior: exprime uma figura particular de pluralidade, a coletividade.

Se o sentimento linguístico, pela sua própria natureza, deve ficar excluido do campo da análise, em contrapartida não devemos desprezar aquilo que inspirou aos gramáticos: as famosas listas de coletivos.

\section{As Tradicionais Listas de Coletivos.}

\section{Transformando uma floresta em herbário.}

As gramáticas costumam apresentar os colefivos sob forma de uma lista, organizada em ordem alfabética, tendo como entrada seja - coletivo, que é em seguida definido, seja o substantivo unitário, seguido do correspondente coletivo. Como a ordem alfabética é extremamente artificial, posto que cômoda, a leitura dessas listas provoca um sentimento de estranheza, proveniente da heferogeneidade das noçōes que se sucedem. O leitor encontra dificuldade em seguir o traço comum que une aquela massa heteróclita, cuja reuniāo longe está de condizer com o seu sentimento lingüistico. Que semelhança nalural se pode observar entre ATILHO e DEZENA, entre SECULO e CAFILA? De pronto se pode dizer que essas listas são o fruto muito mais de uma cerebração sobre a natureza dos referentes que da simples consulia às qualidades semânticas dos vocábulos.

Para que possamos fazer um exame em claro desses repertórios, vamos primeiro proceder a uma classificaçāo dos te:mos contidos nessa "floresta de exemplos". Transformando-a em "ordenado herbário", estaremos mais a cômodo para trabalhar...

A taxionomia que propomos teve por ponto de partida a classificação tradicional, que, como se sảảe, não foi acolhida pela Nomenclafura Gramatical Brasileira. Nascentes e Rocha Lima classificam os coletivos em:

indeterminados $\left\{\begin{array}{l}\text { gerais } \\ \text { partitivos }\end{array}\right.$ 


\section{determinados $\left\{\begin{array}{l}\text { numéricos (ou numerais) } \\ \text { especiais (ou específicos) }\end{array}\right.$}

Rocha Lima $\left({ }^{3}\right)$ assim define essas subclasses: "Os indeterminados não aludem à quantidade dos seres da coleção. Dizem-se gerais, se exoressam un todo; exemplo: exército, que é a totalidade dos militares integrantes dessa Força Armada. E partitivos, se expressam uma parte de um todo: batalhão, que é uma parte do exército. Os determinados, ao contrário, aludem ou à quantidade, ou à qualidade dos seres da coleção. Se à primeira, chamam-se numéricos; exemplos: par, casal, terno, dúzia, dezena, grosa, centena, milheiro. Se à segunda, especiais. Quando se diz, por exemplo, cardume, já se sabe que é um agrupamento de peixes."

Essa classificação tem dois defeitos que saltam à vista. Primeiro, não separa suficientemente os critérios de quantidade e de quaIdade, o que produz uma assimetria conceptual entre os determinados e os indeterminados. Aqueles são definidos apenas pela quantıdade, enquanto estes o são ou pela quantidade ou pela qualidade. $E$ disso decorre o absurdo de um coletivo como EXERCITO ser ao mesmo tempo indeterminado (quanto à quantidade) e determinado (quanto à qualidade). Contra-sensos dessa ordem seriam evitados com uma dupla classificação, que mantivesse em planos ïndependentes os critérios de quantidade e de qualidade.

A segunda falha é simples conseqüência da natureza sintética e confusionista da classificação: ela é incompleta. Há, por exemplo, coletivos indeterminados simultaneamente quanto à quantidade e à qualidade que, no en'anto, não são nem gerais, nem partitivos, como MONTE. Bem entendido, consideramos que só interessa classificar um coletivo como geral se a ele se opõe um ou mais partitivos, o que não é o caso de MONTE.

Eduardo Carlos Pereira $\left({ }^{4}\right)$ e José Marques da Cruz $\left({ }^{5}\right)$ apresentam classificação levemente diferente, que não abriga incoerência, embora seja também excessivamente sintética. Dividem eles os coletivos em:

a) gerais, que abrangem a totalidade dos seres de uma, coleção (EXERCITO);

b) partitivos, que abrangem apenas parte dos seres de uma coleção (BATALHAOO)( $\left.{ }^{8}\right)$; 
c) determinados, que indicam um número ce:to de individuos que constituem uma coleção (CENTENA);

d) indeterminados, que indicam um número incerto (EXERCITO).

Com apoio nesses autores e na lista de coletivos apresentada por J. Mesquita de Carvaiho, em seu Dicionário Prático da Língua Nacional('), produzimos a seguinte classificação:

1. Quanto à formação, os coletivos se dividem em:

A. PRIMARIOS - aqueles vocábulos que são originalmente coletivos. Subdividem-se em:

a) COLETIVOS MOTIVADOS ou TRANSPARENTES - aqueles formados pela adjunção de um sufixo (ou raiz) de valor coletivo à raiz, que exprime a espécie e/Ou a quantidade. Ex.: ARVOREDO, BIBLIOTECA, DEZENA, ete.

b) COLETIVOS ARBITRARIOS OU OPACOS - aqueles cujo significante é totalmente arbitrário, no plano sincrônico. Nesses, a raiz acumula os significados de espécie (ou quaniidade) e de coletivo. Ex.: CALIFA, VARA, FARĀNDOLA, etc.

B. SECUNDARIOS - aqueles vocábulos que são coletivos apenas quando em sentido figurado. São coletivos tropológicos: COLMEIA (por sinédoque), NUVEM (por metáfora), etc.

2. Quanto ao semantismo, os coletivos se c'assificam inicialmente segundo t:ês critérios simultâneos:

A. COMPREENSÃO ou qualidade dos elementos da coletividade;

B. EXTENSÃO ou quantidade dos elementos da coletividade;

C. RELAÇÃO que observam entre si os elementos na coletividade.

2.1. Quanto à compreensão, os coletivos se dividem em:

2.1.1. COLETIVOS VAZIOS - aqueles que não determinam nem genericamente a natureza de seus elementos. Ex.: MUNDO, PORÇAO, CENTENA, etc.

2.1.2. COLETIVOS PLENOS - aqueles que indicam, genérica ou especialmente, a natureza de seus elementos. Ex.: VARA, CONCILIO,

7. CARVALHO, José Mesquita de. Dicionério prifico da língua nacional. 3.a ed., Porto Alegre, Editora Globo, 1954 (2 vol.). 1.० vol., pp. XI-XVI. 
BIBLIOTECA, etc. Estes coletivos se dividem em:

2.1.2.1. COLETIVOS DE ENTES CONTÍNUOS - aqueles que exprimem grandeza temporal ou espacial. EX.: BIENIO, TRIENIO, QUINZENA, SEXTILHA, etc.

2.1.2.2. COLETIVOS DE ENTES DESCONTINUOS. Estes coletivos se subclassificam de acordo com três critérios simultâneos.

2.1.2.2.1. ESPECIFICIDADE. Por este critério, os coletivos se subdividem em:

a) COLETIVOS ESPECÍFICOS - aqueles que sempre se aplicam a uma só espécie de ser. Ex.: CONCILIO, CARDUME, etc.

b) COLETIVOS POLIVALENTES - aqueles que, sem recurso a sentido figurado, podem ser aplicados alternativamente a mais de uma espécie de ser, dentro de um espectro restrito. Ex. ALCATÉIA, CAMBADA, RÉCUA, etc.

2.1.2.2. NATUREZA DA ESPECIE. Por este critério pode-se obter um número indefinido de subdivisões, segundo o maior ou menor grau de sutileza dos critérios. Dentre tantas possíveis, propomos a seguinte subdivisão, que não pretende ser completa:

a) de pessoas: FARÃNDOLA, BATALHÃO, CONCILIO, etc.;

b) de animais R'EBANHO, ALCATÉIA, NUVEM, etc.;

c) de vegetais: FLORA, ATILHO, RAMALHETE, etc.;

d) de partes do organismo animal: CABIDELA, DENTADURA, CA$\mathrm{CHO}$, etc.;

e) de instrumenios: APARELHO, APEIRO, BATERIA, etc.;

f) de produtos: ATADO, BAZAR, PARTIDA, etc.;

g) de detritos: BAGULHO, MORTUALHA, COIVARA, etc.;

h) de objetos verbais descontínuos: ACERVO, CARRADA, CHORRILHO, etc.;

i) de documentos não-verbais: ACERVO, DISCOTECA, FILMO. TECA, etc.;

j) de entes administrativos: COMUNA, CORPORAÇÃO, FEDERAÇÃO, etc.; 
1) de entes geográficos: ARQUIPELAGO, CONSTELAÇÃO.

2.1.2.2.3. HOMOGENEIDADE. Por este critério, os coletivos se subdividem em:

a) COLETIVOS HOMOGENEOS - aqueles que não indicam serem seus elementos necessariamente diferentes uns dos outros. EX.: VARA, NUVEM, CONClLIO, etc.

b) COLETIVOS HETEROGENEOS - aqueles cujos elementos devem apresentar uma diferença entre si. Ex.: DENTADURA, CABIDELA, BIBLIOTECA, etc.

2.2. Quanto à extensão, os coletivos dividem-se em:

2.2.1. COLETIVOS DEFINIDOS - aqueles que indicam uma qualidade delimitada de seres. Subdividem-se em:

a) COLETIVOS DETERMINADOS - aqueles que encerram um número certo de seres. EX.: RESMA, CENTENA, QUINQUENIO, etc.

b) COLETIVOS UNIVERSAIS - aqueles que indicam uma totalidade de seres. Ex.: FAUNA, FLORA, NOBREZA, etc.

2.2.2. COLETIVOS INDEFINIDOS - aqueles que indicam uma quantidade indefinida de seres. Subdividem-se em:

a) COLETIVOS INDETERMINADOS - aqueles que indicam uma quantidade absolutamente indeterminada. Ex. VARA, CONCILIO, NU. VEM, etc.

b) COLETIVOS PARTITIVOS - aqueles que indicam fração de uma coletividade maior. Ex.: BATALHÃO, PELOTAO, REGIMENTO, efc.

2.3. Quanto à relação, os coletivos podem ser classificados segundo dois critérios simultâneos.

2.3.1. EIXO DE ENCONTRO. Por este critéito, os coletivos se subdividem em:

a) COLETIVOS S!NTÓPICOS - aqueles cuja coletividade se encontra reunida num mesmo segmento espacial e/ou temporal. Ex.: VARA, CONCILIO, NUVEM, etc.

b) COLETIVOS ATÓPICOS - aqueles que não indicam se a coletividade se encontra reunida num mesmo segmento espacial e/ous temporal. Ex.: CENTENA, PORÇAO, eic. 
2.3.2. ESTRUTURA. Por este critério classificam-se os coletivos segundo as relações que mantêm entre si, para lá de simples contigüidade física. Por este modo ficam assim agrupados os coletivos:

2.3.2.1. COLETIVOS FACTUAIS - aqueles cuja coletividade é baseada exclusivamente na contigüidade espacial ou temporal. Estes vocábulos apresentam a coletividade como simples fato da natureza ou do acaso, sem atribuir-lhe uma função. Subdividem-se em:

A. COLETIVOS RACEMÁRIOS - aqueles cujos elementos se encontram em estreita contigüidade espacial, podendo mesmo estar ligados uns aos outros. Ex.: PINHA, CACHO, etc.

B. COLETIVOS LASSOS - aqueles cujos elementos se mantêm separados uns dos outros. Ex.: VARA, CARDUME, NUVEM, etc.

2.3.2.2. COLETIVOS FUNCIONAIS - aqueles cuja coletividade se forma por desígnio humano, em visła de uma função a realizar. Subdividem-se em:

A. COLETIVOS AGENTIVOS - aqueles cujos elementos são ativos em relação à função, e esta é interior ao grupo. E.: CONCÍliO, CONCILIABBULO, ełc.

B. COLETIVOS ORDENADOS - aqueles cuja coletividade é passiva em relação à função, e esta é exterior ao grupo. Subdividem-se em:

a) COLETIVOS TECÁRIOS - aqueles cujos elementos se dispõem em sequiência, no mais das vezes segundo uma ordem intelectual. EX.: BIBLIOTECA, ICONOTECA, FILMOTECA, etc.

b) COLETIVOS CONEXOS - aqueles cujos elementos se encontram em estreita, contigüidade, ou bem atados uns aos outros, ou bem empilhados. EX.: CAMBADA, ATILHO, PILHA, efc.

\section{Explorando o herbário}

1. Mais do que simples critérios de classificação, QUANTIDADE, QUALIDADE e RELAÇĀO devem ser considerados como constituintes essenciais da noção de coletivo, pois vocábulo que não encerre qualquer dessas informações não é um coletivo. Vejamos por quê.

A. QUANTIDADE. A razão é óbvia: coletivo é substantivo que exprime uma pluralidade de seres. 
B. QUALIDADE. Os "coletivos vazios" só se apresentam como "coletivos' se seguidos de uma expressão indicadora da qualidade de seus elementos. Tal é o caso de MONTE, que é coletivo em expressōes como UM MONTE DE RAZOES. Entāo, coletivo nāo é MONte, mas a locução inteira, MONTE DE RAZOES. O que se deve reconhecer, no entanto, é a existência de uma sema de pluralidade, presente em todos os substantivos suscetiveis de formar a base de locuçōes coletivas. O sema de plu:alidade é apenas um traço genérico comum a coletivos e a iiens como MONTE, pois estes, a nosso ver, formam um subgrupo particular dos pluralícios, o dos agrupadores, no qual se enquadram vocábulos que estão longe de ser coletivos: PARTE (DE), MAIORIA (DE), PORCENTAGEM (DE), NÚMERO (DE), etc.

C. RELAÇÃO. Já vimos ser a relação integradora dos elementos a característica que distingue a noção de coletividade no seio de um conceito mais amplo, o de pluralidade.

2. Portanto, não são coletivos:

a) os "coletivos vazios";

b) os "coletivos atópicos".

3. Consideremos alguns exemplos de "coletivos atópicos". Que relação imprime entre seus dez elementos um termo como DEZENA? Em um caso como

(1) Ontem João leu uma dezena de livros.

cabe ao termo LIVROS dar a quantidade, e aos demais termos da frase estabelecer a relação integradora dos dez livros. Portanto, a re. lação é ai meramente contextual, externa ao vocábulo DEZENA, que não reúne, mas apenas quantifica os livros. Seja um outro exemplo:

(2) Indo de Castro a Tibagi, vi uma quantidade de pinheiros.

QUANTIDADE DE PINHEIROS não é perfeito equivalente de PINHEIRAL, sobretudo porque QUANTIDADE não indica expressamente a contigüidade espacial dos pinheiros, que bem poderiam estar juntos como dispersos ao longo do trajeto. E força reconhecer, no entanto, que a natureza da relą̧̧ão integradora não é facilmente definível. Embora na maioria das vezes se apresente nitidamente como uma -ontigüidade espacial-temporal (se os elementos da coletividado sao dotados de massa), ou apenas temporal (se os elementos são verbais, como em CHORRILHO), a relação não é sempre clara junto aos coletivos em /-ada/, como LIVRARADA. Em (3) 
(3) Para fazer sua tese, João quer ler uma livrarada. não fica claro se os livros estão, ou não, reunidos em algum lugar. Em todo caso, pode-se admitir que os coletivos em /-ada/ tenham a particularidade de poder apresentar em sucessão temporal os elementos da coletividade significada, sejam eles de natureza verbal cu não. Nesse sentido, consideram-se ainda estes exemplos:

(4) Esse menino comeu uma porcariada antes do almoço.

(5) Esse menino viu uma bicharada hoje de manhã.

4. Os entes contínuos não formam grupos: não se pode tomar como elemento o que é simples medida (dia, ano, verso, etc.). Portanto, não são coletivos termos como TRIENIO, LUSTRO, SECULO, SEXTILHA, TERCETO, etc. De outro modo, e em arrepio do sentimento lingüístico, teríamos que aceitar como coletivos vocábulos como DIA (24 horas), HORA (60 minutos), QUILO (mil gramas), QUILOWATT (mil watts), QUILOMETRO (mil metros), etc.

5. As listas tradicionais não foram constriuídas à luz de uma definição cabal de coletivo, mas segundo a intuição dos gramáticos. E obra puramente empírica, onde a aplicação da analogia foi recoThendo, de pouco em pouco, um sem-número de vocábulos que nada têm de coletivo. Esses procedimento levou os gramáticos a situações de impasse, provenientes do conflito entre o sentimento lingǘstico - como ponto de referência - e a analogia - como instrumento de seleção. Um impasse notável se verificou entre os "coletivos" de enies contínuos. Embora, tenham tomado por coletivos vocábulos como DECEN:O e SECULO, os gramáticos deixaram de lado a coerência e não procederam da mesma forma com relação a ANO, MES, SEMANA, DIA, etc. Ainda por respeito ao sentimento lingüístico, incorreram em outra contradição ao excluírem dos coletivos as medidas de espaço, como QUILOMETRO; de peso, como TONELADA; de potência, como QUILOWATT, etc.

6. E curioso que a Gramática Tradicional não tenha destacado os "coletivos vazios determinados" como substantivos numerais: CENTO, DEZENA, DÚZIA, etc. (8). Poderíamos definir o substantivo numeral como aquele que exprime uma quantidade certa de seres não especificados, e classificá-los em quatro grupos:

a) cardinais: DÚZIA, DEZENA, CENTENA, MIL, MILHÃO, etc.;

b) fracionários: METADE, TERÇO, QUARTO, ełc.;

c) multiplicativos: DOBRO, TRIPLO, QUADRUPLO, efc.; 
d) grupais: DUPLA, TRIO, QUARTETO, QUINTETO, etc.

Não menos curioso for a resistência dos gramáticos em alinhar MIL, MILHÃO, BILHÃO, etc., ao lado de substantivos como CENTENA e DEZENA.

7. Se admitirmos a existência de sufixos para coletivos como prova da pertinência da categoria em estudo, na medida em que os sufixos representam a adoção, por parte da língua, de um meio sistemático para exprimir coletividade, então devemos tomar o coletivo derivado como padrão natural para os demais coletivos.

Todos os coletivos derivados apresentam as seguintes caracieristicas:

a) quan o à qualidade, são plenos, específicos e homogêneos;

b) quanto à quantidade, são indeterminados;

c) quanto à relação, são sintópicos e factuais.

A definição de coletivo como base apenás nesses vocábulos seria, esta: vocábulo que exprime um conjunto de seres da mesma espécie, homogêneos, em número indeterminado, reunidos em um mesmo segmento espacial e/ou temporal, sem uma função determinada. For essa definição ficam excluídos:

a) os "coletivos vazios";

b) os "coletivos heterogênos";

c) os "coletivos definidos";

d) os "coletivos atópicos";

e) os "coletivos funcionais";

f) os "coletivos racemários".

A essa definição, bastante densa, corresponde uma fórmula de parbfrase bem simples. E coletivo todo vocábulo que puder ser satis. fatoriamente definido por: $X$ é um grupo de $Y$. Esta paráfrase implica que não devem ser significativos:

a) o número estrito de elementos;

b) as diferenças individuais entre os elementos;

c) a disposição dos elementos dentro do grupo; 


\section{d) a função do grupo.}

Consideramos que o termo estará satisfatoriamente definido pela paráfrase se esta omitir apenas as informações relativas à grandeza relativa da quaniidade (conjunto grande ou pequeno) e à conotação (nivel da língua, caráter a- ou depreciativo, origem, etc.). De outra parte, "grupo" fica definido como conjunto que é indefinido quanto ao número e lopologia, de seus elementos, mas definido quanto ao espaço e/ou tempo de sua localização.

8. Outra característica dos coletivos derivados está em que o grupo representado pode ser dividido em partes que conservam as mesmas propriedades do todo: um "pinheiral" é divisível em dois pinheirais, uma "iivrarada" em duas, etc. Não possuem essa qualidade os seguintes "coletivos": definidos, partitivos, racemários e agentivos.

9. A lista de "coletivos" elaborada por Mesquita de Carvalho compõe-se de 373 te:mos (excluídas as variantes), dos quals 258 são "coletivos arbitrários". Destes últimos, só 72 se enquadram na. definição proposta no ıtem 7. O número de termos excluídos (186) é significativo: denuncia a na:ureza heteróclita da lista analisada e adianta o caráter redutor de toda, definição de coletivo que busque ser consequiente. Os vocábulos filtrados são os seguintes:

adua
aduba (?)
alavão
anaduva (?)
armento
arquipélago
bagu!ho
bando (9)
barda
batalhão
bisalho
biscate
boana
cáfila
cambada (coria)
canalha
caravana
cardume
caterva
chafardel
choldra

$\begin{array}{ll}\text { chorrilho } & \text { manada } \\ \text { chusma } & \text { manga } \\ \text { constelação } & \text { maromba } \\ \text { coorte } & \text { matilha } \\ \text { coria } & \text { matula } \\ \text { corso } & \text { mesnada } \\ \text { cumilação (?) } & \text { moncalho } \\ \text { enxame } & \text { monturo } \\ \text { escovilha } & \text { mortualha } \\ \text { espicha } & \text { muladar } \\ \text { falange } & \text { muradal } \\ \text { 'faấndola } & \text { oviário } \\ \text { fato } & \text { piara } \\ \text { horda } & \text { pandilha } \\ \text { imundície } & \text { piquete (so!dados) } \\ \text { legião } & \text { piracema } \\ \text { magote } & \text { pléiade } \\ \text { malhada. } & \text { ponta } \\ \text { maloca (malta) } & \text { praga (insetos) } \\ \text { malta } & \text { pugilo } \\ \text { maltesia } & \text { raivel }\end{array}$


revoada

súcia

teoria (anjos) troço (soldados)

tropilha

turba vara

vezeira

10. O único traço comum a todos os termos das listas de coletivo é o pluralidade, e não o de coletivo.

11. Como os gramáticos não distinguiram as noçōes de pluralidade e de coletivo, as suas listas de coletivo representam como que um termo de compromisso entre essas duas noções. As listas não encerram apenas coletivos, mas tampouco abrigám todos os pluralícios. Apresentam os coletivos e os termos pluralicios mais semelhantes a coletivos. Semelhantes ou por falta ou por excesso. Em outras palavias, os gramáticos vislumbram duas noçōes, mas as fundiram numa só.

Importa recuperar essas noções. E preciso delinear a grande classe dos pluralicios, fixando as suas subclasses, entre as quais está a dos coletivo. Para dar uma idéia dessa planta taxionômica dos pluralícios, esboçamos em seguida o setor que engloba os coletivos. No esquema " $X$ " representa $O$ item, e " $Y$ " a expressão especificadora.

\section{A.Coletivos.}

Forma: $X \pm($ de $Y)$.

Paráfrase: $X$ é um grupo de $Y$.

Ex.: item - CARDUME, CARDUME DE TAINHAS; paráfrase CARDUME é uma grupo de peixes; CARDUME DE TAINHAS é um grupo de tainhas.

\section{B. Agrupadores.}

Forma: $X \pm($ de $Y$ ).

Paráfrase: $X$ é uma quantidade.

Divisão:

\section{1. quantificadores:}

1.1. determinados:

1.1.1. numeráricos. Ex.: item - CENTENA (de soldados); paráfrase: CENTENA sāo cem unidades. 
1.1.2. coniinentes. EX.: MATO DE.

1.2. indeterminados:

1.2.1. a,bsolutos. Ex.: MONTE DE.

1.2.2. partitivos. Ex.: MAIORIA DE.

2. ordenadores:

2.1. tecários. Ex.: ALBUM DE.

2.2. conexos. Ex.: PILHA DE.

2.3. racemários. Ex.: CACHO DE.

3. abstratos. Ex.: CONJUNTO DE.

C. Grupos Funcionais.

Forma: $X \pm($ de $Y)$.

Paráfrase: $X$ é um grupo de $Y$, formado para a finalidade tal. Ex.: BIBLIOTECA, MEDA.

D. Medidas.

Forma: $\mathrm{X}$.

Paráfrase: $X$ são tantos $\triangle$.

EX.: SECULO, QUILO, METRO, etc.

E. Grupos de Codependência.

Forma: $X$.

Paráfrase: $X$ é o conjunto de todos os $A$ que man'êm entre si a relação de parentesco $B$. etc.

Ex.: FAMILIA, ASCENDENCIA, DESCENDENCIA, PROLE, CASAL,

12. Um dos grandes absu:dos contidos nas listas tradicionais são vocábulos como CONCILIO, CONCILIÁBULO, CONCLAVE, CONSISTÓRIO, CONGRESSO, etc., os quais têm como idéia central a de atividade e não a de coletividade. Significam uma atividade coletivar e não algo como coletividade ativa. E porque é uma atidade, o CON- 
ClL:O, p. ex., é iniciado, interrompido, adiado, encerrado, mas não pode ser dispersado, com um CARDUME, que por sua vez não é algo que se inicie, interrompa, adie ou encerre.

\section{Conclusão.}

A reflexão que fizemos sobre o substantivo nos permitiu renovar uma constataçāo, já tantas vezes feita, a respeito da Gramática Tradicional. Exatamente porque se trata de uma disciplina empírica, sem compromissos maiores com o rigor científico, mas sim com o simples intuicionismo, encerra tanto de inconseqüências quanto de boas idéias. Portanto, não deve ser acatada sem crítica nem tampouco recusada em bloco. A Gramática. Tradicional é trigo a ser joeirado.

Quanto à própria noção de coletivo, ficamos sem juizo definitivo sobre suas pertinência língüístico. Aliás, como se prova a existência de uma categoria semântica? As categorias formais, como substar,tivo, adjetivo, masculino, feminino, etc., se comprovam por criterios formais, como distribuição, comutação, efeito de concordância, etc. Já para as semânticas não há uma sólida tradição a consultar Categorias semânticas tais como substantivo próprio e comum ficam amplamente evidenciadas por notáveis repercussões no plano sintático (restriçōes à determinação, p. ex.), a ponto de se poder incluí-las entre as categorias sintático-semânticas. A noção de coletivo deve ser manipulada com argumentos semânticos, os quais não se manifestam por evidência. Em todo caso, esperamos ter contribuído para o estudo desse assunto ao propor o noção de "vocábulo pluralício" e uma definição analítica de coletivo.

\section{RESUME}

L'auteur analyso la notion de nom collectif, dont il essaie de dégager les traits essentiels. li commence par opposer les concepts de pluriel et de collectif, pour ensuite mettre en question l'existence mème des collectifs.

Lauteur critique 'es classifications traditionnelles des collectifs ef en propose une nouvelle, qui lui permet d'établir une définition analytique de collectif. A partir d'une distinction entre nom "pluralisium" (pluralício) et nom collectif, l'auteur montre le caractère empirque du concept de collectif renfermé par les listes habituelles de collectifs, dent la promiscuité es: aussi dénoncée.

\section{NOTAS}

1. E o que a Gramática Tradicional busca esclareczr quando define o coletivo como o substantivo que já no singular exprime diversos seres.

2. E bem conhecido o faso de que a lingua recorta o universo em objetos e os clessifica segundo os padróes cultura.s próprios à comunidade de seus falantes, 
e que seus critérios nem sempre coincidem com os do cientista ou do filósofo. Nesse sentido, basta recordar que as línguas alemã e inglesa conferem ao dedo dois nomes distintos, segundo seja da mão ou do pé.

3. ROCHA LIMA, Carlos Eduardo. Gramática normativa da língua portuguesa. 15.: đ. (refundida), Rio de Janeiro, José O.ympio, 1972. P. 63.

4. PEREIRA, Eduardo Carlos. Gramática expositiva. Curso superior. 100.0 ed., São Paulo, Co npanhia Editora Nacional, s/d. P. 82.

5. MARQUES DA CRUZ, José. Português prático. 23. a ed., São Paulo, Ediçōes Melhoramertos, 1953. P. 32.

6. Afora cs casos clássicos de EXÉRCITO e BATALHÃO, a exemplificação que faz Eduardo Carlos Pereira de coletivos gerais e partitivos é insustentável:

COLETIVO GERAL
exército
tropa
cafezal
povo
multidioo
centena
assembléia

\author{
COLETIVO PARTITIVO \\ batalhão \\ lote \\ talhão \\ multidäo (do povo) \\ parte (da multidāo) \\ metade (da centena) \\ maioris
}

Então, assim como o exército se compöe de batalhöes, o povo 6 formado de multidjes e uma assembléia de maiorias (1)? E partitivo apenas aquele coletivo que designa uma fração em que se divide uma coletividade maior, sendo esta a referência definidora da fração. Ora, LOTE, TALHÃO e MULTIDĀO nāo fazem raferência necesśśria a TROPA, CAFEZAL e POVO. E quanto a PARTE, METADE e MAIORIA, não é pacífico que sejam coletivos, como se verá adiante.

8. A categor"a tradicioncl mais próxima dos "substantivos numerais"é a dos "coletivos numéricos", a qual acolhe todos os coletivos determinados quanto ao número, sejam eies "vazios" ou "plenos". Poptanto, figuram entre os coletivos numéricos vocábulos com CASAL, que não exprimem apenas número, mas também a qualidade dos indivíduos. Houve, todavia, uma gramática que definiu o coletivo numé:ico da ta: maneira, que sua extensão lógica fica contida no interior dos "substantivos numerais". Trata-se de P. Eurípedes Olímpio de Oliveiro e Sousa, que assim definiu o que chamava coletivos numbrais; "Coletivo numeral é o nome quo derivaclo de adjetivo cardinal ou multiplicativo designa agrupamen. to ou pertença a um mesmo conjunto par ou impar". Alguns de seus exemplos não fogem ao espírito historicista e arcaizante que preside à sua obra: TERNO, CADERNO, NOVENA, CENTENA, MILENA. (Noçöos de gramática e do língua portugueca. 2.a ed., revista e aumentada, Säo Paulo, Editora Civilizaçäo Brasileira S.A./Companhia Edifora Nacional, 1957. P. 159).

9. Julgamos lícito assimilar os coletivos polivalentes aos específicos, dado que seu campo de aplicaçāo é restrito, permitindo ver nos seus diversos empregos 